\title{
BRIEF

\section{Impact of a Student-Run Clinic on Emergency Department Utilization}

Anjali B. Thakkar, MD, MBA; Pooja Chandrashekar, BA; Wei Wang, PhD; Bonnie B. Blanchfield, ScD, CPA, MS

BACKGROUND AND OBJECTIVES: Student-run clinics (SRCs) provide primary care access to low-income patients who would otherwise pursue more expensive care, such as visits to emergency departments (ED). Decreasing inappropriate ED utilization offers an opportunity to create value in the health care system. However, to date, no SRC has rigorously studied this. This study examines whether increased access to ambulatory care through an SRC, the Crimson Care Collaborative (CCC), is associated with decreased ED utilization, providing value to payers and providers, and justifying investment in SRCs.

METHODS: We conducted a 5-year retrospective analysis of 796 patients to determine if ED utilization changed after patients enrolled in CCC. We used patient-level ED visit data to estimate the average change in ED utilization. A regression analysis examined the impact of demographic and clinical variables on changes in ED utilization.

RESULTS: Average per-patient ED utilization significantly $(P<0.001)$ decreased by $23 \%, 50 \%$, and $48 \%$ for patients enrolling in CCC from 2013 to 2015, respectively. Following enrollment in CCC, average ED utilization decreased by 0.39 visits per patient per year. This translates to 62.01 avoided ED visits annually, and estimated payer savings of $\$ 84,148$, representing $68 \%$ of the clinic's direct operating costs.

CONCLUSIONS: CCC created value to payers and providers from 2013-2015 by providing a lower-cost source of care and increasing ED capacity for more emergent and appropriate care. This study suggests that SRCs can create financial value for both payers and providers while also providing an avenue to teach value-based care in medical education.

(Fam Med. 2019;51(5):420-3.)

doi: 10.22454/FamMed.2019.477798

tudent-run clinics (SRCs) provide primary care access to patients who would otherwise pursue expensive avenues of care, such as visits to emergency departments (EDs)., ${ }^{1,2}$ Decreasing inappropriate ED utilization is a major opportunity to generate health care value. However, the impact of SRCs on ED utilization is unknown. ${ }^{3-8}$ To address this gap, we studied the value created by the Crimson Care Collaborative (CCC), a Harvard Medical School-affiliated network of seven SRCs providing after-hours primary care in the Boston area. Established in 2011, the CCC clinic at Massachusetts General Hospital-Internal Medicine Associates operates from 5:30 pm to 7:30 pm on Tuesdays for 49 weeks each year. For 39 weeks, 7 to 10 patients are seen each night; for 10 weeks during the summer, the clinic operates at half capacity. We hypothesized that increased outpatient access through CCC would be associated with decreased ED utilization.

\section{Methods}

A retrospective longitudinal analysis was conducted to quantify the change in ED utilization before and after patients enrolled at CCC.

\section{Study Population}

The study population included all 796 adult patients who enrolled at CCC between October 1, 2010 and September 30, 2015. Annual patient cohorts consisting of newly enrolled CCC patients were created for each fiscal year.

\section{Data Collection}

Patient data was obtained from the hospital's clinical data registry. ${ }^{9} \mathrm{CCC}$ visits were obtained from the clinic's RedCap database. Socioeconomic status was approximated using US census data, which lists the mean per capita income associated with a patient's home zip code. The Deyo adaptation of the Charlson Comorbidity Index (CCI) was used as a proxy for health status..$^{10}$

From University of California, San Francisco Medical Center (Dr Thakkar); Crimson Care Collaborative, Boston, MA (Dr Blanchfield and Ms Chandrashekar); and Brigham and Women's Hospital and Harvard Medical School (Drs Wang and Blanchfield). 
Data Analysis

The primary outcome - change in per patient ED utilization - was calculated using annualized ED utilization in the 18 months before and after CCC enrollment. Independent variables included gender, age, language, race, distance to clinic, marital status, insurance type, socioeconomic status, smoking status, body-mass index, CCI, and annual CCC utilization.

Descriptive analyses characterized the cohorts. Two-sided Wilcoxon signed-rank tests estimated if changes in ED utilization were significant. Regression analysis assessed the influence of the named demographic and clinical covariates on changes in ED utilization. SAS v 9.4 software was used for statistical analysis. ${ }^{11}$

Cost savings were calculated using the median ED charge of $\$ 1,233 .{ }^{12}$ The 2015 inflation adjusted charge of $\$ 1,357$ was multiplied by the average number of avoided visits per year to compute annual cost savings. Avoided visits were calculated by multiplying the average annual cohort size by the observed average annual per patient reduction in ED utilization. The Partners Healthcare Institutional Review Board approved this study.

\section{Results}

Patients were predominantly under age 65 years, white, English-speaking, commercially-insured, lived within 10 miles of CCC, and had annual per capita incomes between $\$ 15,000$ and $\$ 40,000$ (Table 1).

\section{ED Utilization}

In the 2012 cohort, average per patient ED utilization increased by 80\% $(P<0.03)$ after CCC enrollment. For the three subsequent cohorts, average per patient ED utilization decreased by $23 \%, 50 \%$, and $48 \%$ $(P<0.001)$ respectively. During these 3 years, ED utilization decreased by an average 0.39 visits per year per patient (Figure 1).

Regression analysis revealed that for each additional CCC visit, ED utilization decreased by 0.41 visits per patient $(P<0.0001)$. Although age and smoking were correlated with ED utilization $(r=-0.09,0.11$; $P=0.008,0.003$, respectively), they were not significant in the final model. No other characteristics were related to change in ED utilization.

\section{Financial Impact}

Assuming a 5-year annual cohort size of 159 patients and an annual reduction of 0.39 visits per patient, $62.01 \mathrm{ED}$ visits were avoided each year, amounting to $\$ 84,148$ in annual savings- $68 \%$ of the clinic's direct operating costs.

\section{Discussion}

In the 2013,2014 , and 2015 cohorts, the observed decrease in ED utilization following CCC enrollment suggests that patients will seek after-hours outpatient care, if available. The increase in ED utilization in the 2012 cohort is likely due to low patient engagement, fragmented staffing, and leadership turnover during the clinic's pilot period. From 2013 onwards, clinic staffing and leadership stabilized and a sustained decrease in ED utilization was observed.

Our results are notable for three reasons: (1) quantifying the clinic's impact on ED utilization can guide QI initiatives, (2) quantification of value provides justification for the SRC model, and (3) it is proof-ofconcept that SRCs can train future health care professionals in valuebased care.

\section{Quality Improvement}

QI initiatives can educate patients around appropriate ED use and incentivize longitudinal use of CCC. A key next step is understanding the drivers for ED and CCC utilization. This could drive disease-specific initiatives to shift care to appropriate settings.

Although the financial implications of reduced utilization do not directly impact CCC's operating budget, shifting care to a lower-cost setting benefits the host hospital and can justify budget increases for CCC QI initiatives.

\section{Value for Society}

Our study suggests SRCs create value to payers and providers by providing alternative, more appropriate sources of care. We assume reductions in ED visits reflect shifts of nonurgent care from the ED to the outpatient clinic, freeing up ED capacity for higher-acuity cases. CCC likely creates value for patients by providing social and behavioral health services in the clinic, helping patients establish primary care relationships, and offering after-hours care. $^{13}$

\section{Value-Based Care in Medical Curriculum}

Medical school is the ideal time to educate young physicians about payment models, and the value of care they deliver. The nearly 100 medical schools hosting SRCs provide an ideal opportunity to apply theoretical knowledge around value-based care. $^{14}$

\section{Limitations}

Although we only examined ED utilization within the Partners Healthcare system, given Partners' broad network, we believe our results account for the majority of patients' ED usage. Because we did not classify ED visits as urgent or nonurgent, we are unable to draw conclusions about the acuity of avoided ED visits. Lastly, given that our study looks at a snapshot in time, it is possible that as time progresses and the SRC helps high-ED utilizers access primary care, cost savings may diminish.

\section{Conclusion}

This study is the first to examine the impact of SRCs on ED utilization. Our approach is a proof of concept that SRCs can be positioned as a platform for teaching students about value in health care delivery. 
Table 1: Demographic Characteristics of Annual Crimson Care Collaborative (CCC) Patient Cohorts Enrolling Between 2011 and 2015

\begin{tabular}{|c|c|c|c|c|c|c|c|c|c|c|c|c|}
\hline & \multicolumn{12}{|c|}{ CCC Enrollment Fiscal Year } \\
\hline & \multicolumn{2}{|c|}{ Total } & \multicolumn{2}{|c|}{2011} & \multicolumn{2}{|c|}{2012} & \multicolumn{2}{|c|}{2013} & \multicolumn{2}{|c|}{2014} & \multicolumn{2}{|c|}{2015} \\
\hline & $\#$ & $\%$ & $\#$ & $\%$ & $\#$ & $\%$ & $\#$ & $\%$ & $\#$ & $\%$ & $\#$ & $\%$ \\
\hline Number of Patients & 796 & 100 & 166 & 21 & 154 & 19 & 162 & 20 & 154 & 19 & 160 & 20 \\
\hline Male & 380 & 48 & 74 & 45 & 71 & 46 & 77 & 48 & 75 & 49 & 83 & 52 \\
\hline \multicolumn{13}{|l|}{ Age } \\
\hline$>65$ & 199 & 25 & 48 & 29 & 50 & 32 & 35 & 22 & 35 & 23 & 31 & 19 \\
\hline $55-64$ & 130 & 16 & 33 & 20 & 20 & 13 & 27 & 17 & 29 & 19 & 21 & 13 \\
\hline $45-54$ & 141 & 18 & 27 & 16 & 29 & 19 & 26 & 16 & 27 & 18 & 32 & 20 \\
\hline $35-44$ & 131 & 16 & 25 & 15 & 28 & 18 & 29 & 18 & 20 & 13 & 29 & 18 \\
\hline $25-34$ & 174 & 22 & 33 & 20 & 27 & 18 & 40 & 25 & 39 & 25 & 35 & 22 \\
\hline $18-24$ & 21 & 3 & 0 & 0 & 0 & 0 & 5 & 3 & 4 & 3 & 12 & 8 \\
\hline \multicolumn{13}{|l|}{ Race/Ethnicity } \\
\hline White & 510 & 64 & 110 & 66 & 102 & 66 & 105 & 65 & 89 & 58 & 104 & 65 \\
\hline Black & 104 & 13 & 2 & 12 & 18 & 12 & 21 & 13 & 25 & 16 & 20 & 13 \\
\hline Hispanic & 69 & 9 & 17 & 10 & 14 & 9 & 17 & 10 & 11 & 7 & 10 & 6 \\
\hline Asian & 56 & 7 & 13 & 8 & 14 & 9 & 7 & 4 & 11 & 7 & 11 & 7 \\
\hline Other & 57 & 7 & 6 & 4 & 6 & 4 & 12 & 7 & 18 & 12 & 15 & 9 \\
\hline \multicolumn{13}{|l|}{ Primary Language } \\
\hline English & 679 & 85 & 143 & 86 & 126 & 82 & 136 & 84 & 135 & 88 & 139 & 87 \\
\hline \multicolumn{13}{|l|}{$\begin{array}{l}\text { Distance From Home } \\
\text { to Clinic (Radius) }\end{array}$} \\
\hline$\leq 1$ mile & 57 & 7 & 12 & 7 & 8 & 5 & 15 & 9 & 15 & 10 & 17 & 11 \\
\hline$>1$ mile; $\leq 2.5$ miles & 79 & 10 & 13 & 8 & 19 & 12 & 17 & 10 & 20 & 13 & 19 & 12 \\
\hline$>2.5$ miles $; \leq 5$ miles & 181 & 23 & 43 & 26 & 37 & 24 & 43 & 27 & 43 & 28 & 44 & 28 \\
\hline$>5$ miles; $\leq 10$ miles & 175 & 22 & 45 & 27 & 40 & 26 & 38 & 23 & 32 & 21 & 43 & 27 \\
\hline$>10$ miles; $\leq 25$ miles & 127 & 16 & 29 & 17 & 37 & 24 & 26 & 16 & 27 & 18 & 22 & 14 \\
\hline$>25$ miles; $\leq 50$ miles & 44 & 6 & 18 & 11 & 6 & 4 & 9 & 6 & 9 & 6 & 7 & 4 \\
\hline$>50$ miles; $\leq 216$ miles & 17 & 2 & 3 & 2 & 2 & 1 & 8 & 5 & 6 & 4 & 3 & 2 \\
\hline Incorrect address* & 17 & 2 & 3 & 2 & 5 & 3 & 6 & 4 & 2 & 1 & 5 & 3 \\
\hline \multicolumn{13}{|l|}{ Payer } \\
\hline Medicare & 136 & 17 & 40 & 24 & 28 & 18 & 16 & 10 & 28 & 18 & 24 & 15 \\
\hline Medicaid, MassHealth, NHP & 224 & 28 & 40 & 24 & 36 & 23 & 55 & 34 & 45 & 29 & 48 & 30 \\
\hline Commercial & 393 & 49 & 73 & 44 & 83 & 54 & 83 & 51 & 73 & 47 & 81 & 51 \\
\hline Uninsured, self-pay & 43 & 5 & 13 & 8 & 7 & 5 & 8 & 5 & 8 & 5 & 7 & 4 \\
\hline \multicolumn{13}{|l|}{ Socioeconomic Status } \\
\hline$<\$ 10,000$ & 4 & 1 & 0 & 0 & 1 & 1 & 0 & 0 & 3 & 2 & 0 & 0 \\
\hline$<\$ 15,000$ & 100 & 13 & 19 & 11 & 21 & 14 & 28 & 17 & 18 & 12 & 25 & 16 \\
\hline$\$ 15,001-\$ 25,000$ & 220 & 28 & 54 & 33 & 40 & 26 & 56 & 35 & 54 & 35 & 52 & 33 \\
\hline$\$ 25,001-\$ 40,000$ & 240 & 30 & 57 & 34 & 60 & 39 & 56 & 35 & 52 & 34 & 51 & 32 \\
\hline$\$ 40,001-\$ 75,000$ & 104 & 13 & 28 & 17 & 25 & 16 & 16 & 10 & 22 & 14 & 23 & 14 \\
\hline$\geq \$ 75,001$ & 16 & 2 & 5 & 3 & 2 & 1 & 2 & 1 & 3 & 2 & 4 & 3 \\
\hline Unknown & 17 & 2 & 3 & 2 & 5 & 3 & 4 & 2 & 2 & 1 & 5 & 3 \\
\hline
\end{tabular}

*Patients living within a radius greater than 216 miles were no longer in Massachusetts. Therefore, it was hypothesized that the wrong address was on file for these patients and this field was left blank. 
Figure 1: Annualized Emergency Department (ED) Utilization Pre- and Postenrollment in CCC for Each Annual Cohort

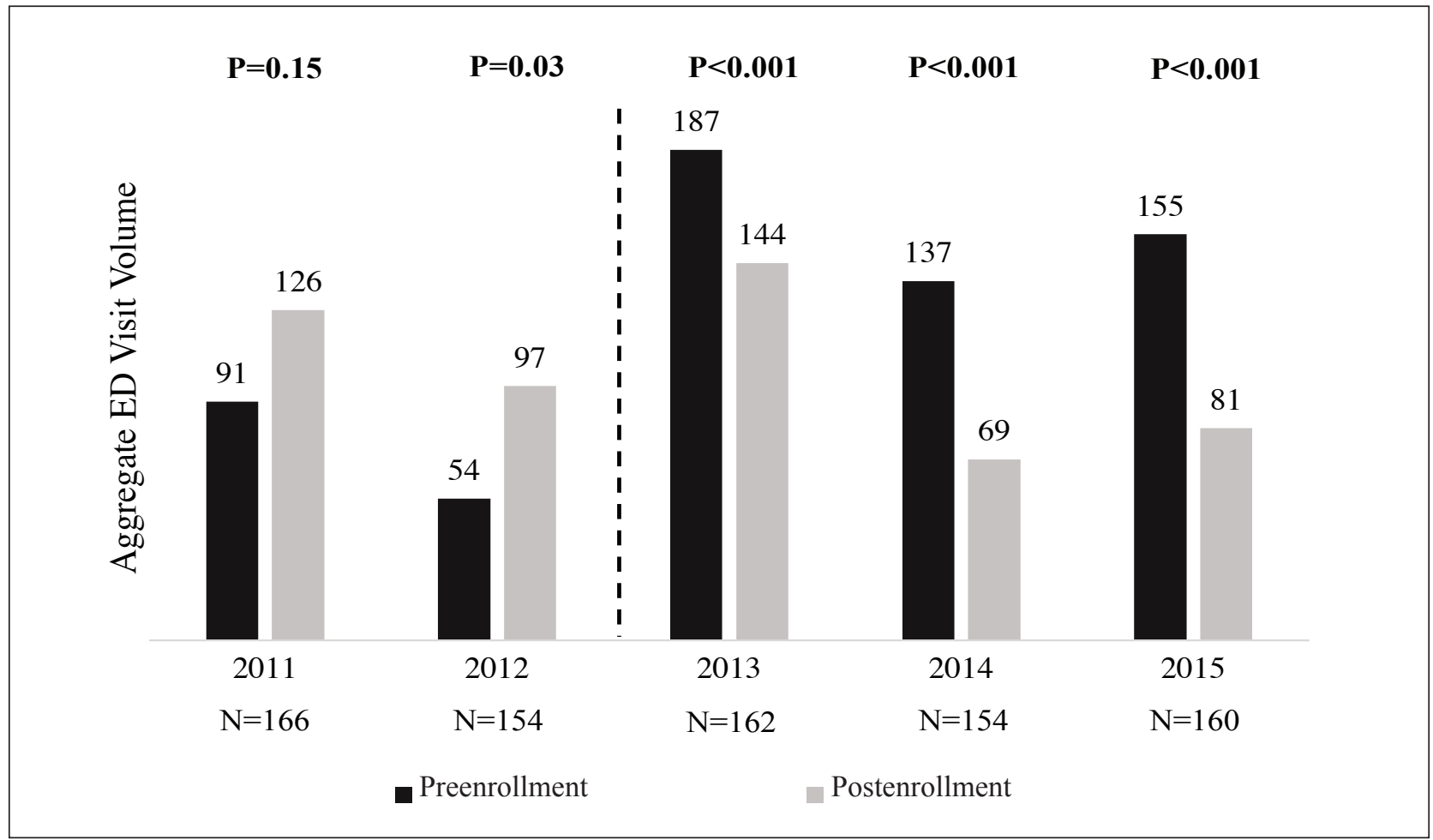

ACKNOWLEDGMENTS: The authors thank Susan Edgman-Levitan, and Drs Marya Cohen, Rebecca Berman, Thalia Krakower, and Amanda Johnson for providing historical context about the clinic's operations prior to the years when the authors joined the institution.

FINANCIAL SUPPORT: Crimson Care Collaborative is supported by the generosity of the John D. Stoeckle Center for Primary Care Innovation located at the Massachusetts General Hospital. Funding for statistical analysis was provided by Harvard Catalyst.

PRESENTATIONS: Preliminary findings from these data were presented as a poster at the National Society for General Internal Medicine Conference in April 2017 in Washington, DC, and at the New England Society for General Internal Medicine Conference in March 2017 in Boston, MA. The findings were also presented as an oral presentation at the Society for Student-Run Free Clinics Conference in February 2017, in Los Angeles, CA.

CORRESPONDING AUTHOR: Address correspondence to Dr Bonnie B. Blanchfield, 1620 Tremont Street,Boston, MA 02120. 617-5256651. bblanchfield@BWH.harvard.edu.

\section{References}

1. Smith S, Thomas R III, Cruz M, Griggs R, Moscato B, Ferrara A. Presence and characteristics of student-run free clinics in medical schools. JAMA. 2014;312(22):2407-2410.

2. Weinick RM, Burns RM, Mehrotra A. Many emergency department visits could be managed at urgent care centers and retail clinics. Health Aff (Millwood). 2010;29(9):1630-1636.
3. Petersen LA, Burstin HR, O’Neil AC, Orav EJ, Brennan TA. Nonurgent emergency department visits: the effect of having a regular doctor. Med Care. 1998;36(8):1249-1255.

4. Truven Health Analytics. Avoidable Emergency Department Usage Analysis: Research Brief. http://img.en25.com/Web/TruvenHealthAnalytics/EMP_12260_0113_AvoidableERAdmissionsRB_WEB_2868.pdf. Accessed July 30, 2017.

5. Petterson SM, Rabin D, Phillips RLJ Jr, Bazemore AW, Dodoo MS. Having a usual source of care reduces ED visits. Am Fam Physician. 2009;79(2):94.

6. Sarver JH, Cydulka RK, Baker DW. Usual source of care and nonurgent emergency department use. Acad Emerg Med. 2002;9(9):916923.

7. Porter ME. What is value in health care? N Engl J Med. 2010;363(26):2477-2481.

8. Lee TH. Putting the value framework to work N Engl J Med. 2010;363(26):2481-2483.

9. Research Information Science and Computing. Research Patient Data Registry. https:// rc.partners.org/research-apps-and-services/ identify-subjects-request-data\#research-patient-data-registry. Accessed July 30, 2017.

10. Deyo RA, Cherkin DC, Ciol MA. Adapting a clinical comorbidity index for use with ICD-9CM administrative databases. J Clin Epidemiol. 1992;45(6):613-619.

11. SAS (software). Version 9.4. Cary, NC: SAS; 2017.

12. Caldwell N, Srebotnjak T, Wang T, Hsia R. "How much will I get charged for this?" Patient charges for top ten diagnoses in the emergency department. PLoS One. 2013;8(2):e55491.
13. O’Malley AS. After-hours access to primary care practices linked with lower emergency department use and less unmet medical need. Health Aff (Millwood). 2013;32(1):175-183.

14. Smith TM. Value-based care, an elusive concept, enters the curriculum. Accelerating Change in Medical Education. https://wire. ama-assn.org/education/value-based-careelusive-concept-enters-curriculum. Published December 5, 2016. Accessed July 30, 2017. 